\title{
AS TRANSFORMAÇÕES NO MODELO DE DESENVOLVIMENTO CHINÊS E SEUS IMPACTOS NA ESTRUTURA PRODUTIVA: SERÁ O FIM DA "CHINA BARATA"?
}

\section{$\underline{\text { RESUMO }}$}

Caroline Miranda Brandão ${ }^{1}$

Caroline Giusti de Araújo ${ }^{2}$

Antônio Carlos Diegues $\mathrm{Jr}^{3}$

O objetivo deste trabalho é compreender se está ocorrendo o fim da China barata, ou seja, se há um aumento dos preços dos bens exportados pela indústria chinesa. A fim de verificar se a China está encarecendo sua produção a análise será realizada sob uma perspectiva estrutural, para os anos 1990 até anos 2000. Dessa forma, será realizado um estudo que busca verificar se existe uma mudança na estrutura produtiva em direção a bens intensivos em tecnologia. Para isso serão utilizados indicadores de comércio internacional e de produção industrial. Além disso, será analisada as modificações na estrutura salarial chinesa e como esse movimento impacta na competitividade do país, através de um aumento nos preços. Essa avaliação será feita por meio de indicadores como a evolução da massa salarial chinesa e a produtividade do trabalho. Por fim, será realizada uma comparação de preços relativos da China com principais parceiros comerciais dos EUA na exportação de bens para o mercado americano. Logo, será possível verificar o impacto de tais mudanças, da estrutura produtiva e salarial, para a composição dos preços de bens industriais exportados.

Palavras-chave: Política industrial. Economia chinesa. Estrutura produtiva. Inovação. Comércio internacional.

Código JEL: O14, O25

Área ABEIN: Área 1 - Indústria e competitividade

\section{THE TRANSFORMATIONS IN THE CHINESE DEVELOPMENT MODEL AND ITS IMPACTS ON THE PRODUCTIVE STRUCTURE: WILL BE THE END OF "CHINA CHEAP"?}

\section{ABSTRACT}

The aim at this paper is to understand if the end of China cheap, that is, if there is an increase in the prices of goods exported by Chinese industry. In order to verify if China is increasing its production the analysis will be carried out from a structural perspective for the years 1990 to the year 2000. Thus, a study will be carried out to verify if there is a change in the productive structure toward the intensive goods. For this purpose indicators of international trade and industrial production will be used. In addition, the Chinese salary structure will be verified and how it will impact the competitiveness of the country through indicators of competitiveness and structural salary. Finally, a comparison of relative prices of China with major US trading partners in the export of goods to the US market will be made. Therefore, it will be possible to verify the impact of such changes, in the productive and wage structure, for the composition of the prices of exported industrial goods.

Keywords: Industrial policy. Chinese economy. Productive structure. Innovation. International trade.

\footnotetext{
${ }^{1}$ Doutoranda em teoria econômica pelo instituto de economia da Unicamp (IE/UNICAMP).

${ }^{2}$ Mestranda em desenvolvimento econômico pelo instituto de economia da Unicamp (IE/UNICAMP).

${ }^{3}$ Professor doutor do instituto de economia da Unicamp (IE/UNICAMP).
} 


\section{Introdução}

A China tem se tornado uma das economias mais importantes do mundo, haja vista suas altas taxas de crescimento há mais de duas décadas. O país apresentou crescimento do PIB de 10,14\% a.a., entre 1980 e 2000, e de 10,84\% a.a., entre 2000 e 2010. Já os EUA, a maior economia do mundo, apresentaram crescimento de 3,36\% a.a. e $1,84 \%$ a.a., para os mesmos períodos, respectivamente (UNCTAD, 2014).

O desempenho chinês atual é resultado de uma série de mudanças estruturais que ocorreram a partir da década de 1970. Durante esse período, o governo teve como objetivo aumentar a participação do país no comércio internacional e atrair investimentos externos. Verificou-se que a economia chinesa se tornou uma das principais receptoras de investimento direto estrangeiro, haja vista que o país representava $0,11 \%$ de todos os fluxos mundiais de IDE (Investimento Direto Estrangeiro), em 1980, passando a 9,1\%, em 2012 (UNCTAD, 2014). Como discutido por Sarti e Hiratuka (2010), a China direcionou e deslocou diversos investimentos, não só da Ásia, como do resto do mundo, sendo peça fundamental na configuração da divisão internacional do trabalho e na escolha de investimentos internacionais.

Dessa forma, durante a década de 1980, a China atraiu investimentos oriundos de setores mais intensivos em trabalho, devido aos baixos salários. Porém, a partir de 1986, houve o início da segunda fase da abertura ao IDE, na qual, o governo adotou medidas para mudar a estrutura setorial dos investimentos diretos recebidos buscando direcionar os investimentos para a indústria de transformação e para os setores de mais alta tecnologia (ACIOLY, 2005). Portanto, o que se verifica é uma tentativa do governo de deslocamento dos investimentos de setores menos intensivos em tecnologia para setores mais intensivos. No entanto, esta mudança na produção enseja uma mão de obra qualificada, o que implica salários maiores que os tradicionalmente conhecidos como o cerne da vantagem competitiva chinesa (NONNENBERG E MESENTIER, 2012).

Com isso, infere-se que este intuito de trazer indústrias mais intensivas em tecnologia acabaria por promover um "encarecimento" ao produto exportado chinês. Avalia-se, então, que esse aumento de preço se daria sob duas perspectivas: (i) o produto de maior intensidade tecnológica, que apresenta um preço médio maior que os produtos intensivos em trabalho e/ou recursos naturais; (ii) a produção de bens intensivos em tecnologia promove um aumento salarial, que pode ser repassado ao preço do bem final.

Neste sentido busca-se compreender se é possível dizer que há uma trajetória rumo ao fim da China barata. Faz-se uma ressalva, no entanto, que o aumento salarial não representa apenas uma elevação de custos produtivos e, portanto, preços, mas sim uma consequência da mudança na estrutura produtiva, pois a produção de bens intensivos em tecnologia requer maior qualificação técnica, que eleva os salários pagos nesses setores. Dessa forma, o objetivo central desse trabalho é verificar se houve uma mudança na estrutura produtiva, ou seja, se houve um processo de catching up.

A partir disso, o estudo será dividido em três partes: (i) indicadores de comércio internacional e produção industrial; (ii) análise de massa salarial e produtividade; (iii) impacto sobre os preços de bens industriais exportados da China para os EUA. A partir dos indicadores de comércio e indústria construídos no item (i) será possível observar a mudança na estrutura produtiva. Já no item (ii) será possível verificar a trajetória dos salários e sua relação com a produtividade. Na terceira seção será realizada uma comparação de preços relativos das exportações chinesas a fim de compreender se a mudança na estrutura produtiva e de salários possui desdobramentos para os preços chineses. Por fim serão apresentadas as considerações finais. 


\section{Estrutura Produtiva}

A análise da mudança na estrutura produtiva será realizada com indicadores divididos segundo tipo de tecnologia ${ }^{4}$. Além disso, o estudo é separado em duas partes: (i) indicadores de comércio internacional e (ii) indicadores de produção industrial.

Para que se possa observar se há uma convergência da produção chinesa com países mais desenvolvidos, adotar-se-á os dados americanos. Optou-se pela comparação com a economia americana, pois, trata-se de um país desenvolvido, que possui uma estrutura produtiva sofisticada.

Os EUA foi o $10^{\circ}$ país em renda per capita no ano de 2013 (WORLD BANK, 2013). Além disso, o país apresenta uma estrutura produtiva mais complexa voltada para a produção de bens mais intensivos em tecnologia, ou seja, com maiores encadeamentos interssetoriais. Segundo World Bank (2013), os EUA apresentaram em 2013 uma participação de 17,8\% do total exportado pertencente a produtos de alta tecnologia. Ressalta-se que este é um indicador superior ao de países de alta renda ${ }^{5}$ $(16,4 \%)$ e países de alta renda pertencentes à OCDE $(17 \%)$.

Somado a isso, os EUA apresentaram altas taxas de investimento em P\&D em 2012. Enquanto países de alta renda gastaram 2,4\% em relação ao PIB e países de alta renda pertencentes à OCDE, gastaram 2,6\%, os EUA gastaram 2,8\%. (WORLD BANK, 2012). Portanto, se houver uma aproximação da estrutura produtiva chinesa com a americana, é possível dizer que houve aumento significativo de sofisticação na produção chinesa.

\subsection{Comércio Internacional}

Ao observar o Gráfico 1, pode-se perceber um aumento da participação das exportações chinesas nos segmentos diferenciado e escala, e uma diminuição da participação nos segmentos intensivos em trabalho. Sendo assim, em 2014, a maior parte das exportações do país se tornaram de bens mais intensivos em tecnologia.

\footnotetext{
${ }^{4}$ Como os dados da UNIDO são disponibilizados apenas em dois dígitos para cada setor, a classificação por tipo de tecnologia foi simplificada. Dessa maneira, os setores classificados como intensivos em recursos naturais incluem os setores: fabricação de produtos alimentícios e bebidas, fabricação de produtos do fumo, fabricação de produtos de madeira, fabricação de celulose, papel e produtos de madeira, fabricação de coque, refino de petróleo, elaboração de combustíveis nucleares e produção de álcool, fabricação de produtos de minerais não metálicos. Os setores baseados em ciência incluem o setor: fabricação de máquinas para escritório e equipamentos de informática. Os setores intensivos em trabalho incluem: fabricação de produtos têxteis, confecção de artigos do vestuário e acessórios, preparação de couros e artefatos de couro, artigos de viagem e calçados, fabricação de produtos de metal - exclusive máquinas e equipamentos, fabricação de móveis e indústrias diversas. Os setores intensivos em escala incluem: fabricação de produtos químicos, edição, impressão e reprodução de gravações, fabricação de artigos de borracha e de material plástico, metalurgia básica, fabricação e montagem de veículos automotores, reboques e carrocerias, fabricação de outros equipamentos de transporte. Os setores diferenciados incluem: fabricação de máquinas e equipamentos, fabricação de máquinas, aparelhos e materiais elétricos, fabricação de material eletrônico e de aparelhos e equipamentos de comunicações, fabricação de equipamentos de instrumentação médico-hospitalares, instrumentos de precisão e óticos, equipamentos para automação industrial, cronômetros e relógios.

${ }^{5}$ Classificação World Bank (2016). Países de alta renda: renda per capita é se $\$ 12.736$ ou mais. Engloba 80 países; Países de alta renda pertencentes à OCDE: Austrália, Áustria, Bélgica, Canadá, Chile, República Tcheca, Dinamarca, Estônia, Finlândia, França, Alemanha, Grécia, Hungria, Islândia, Irlanda, Itália, Israel, Japão, Coréia do Sul, Luxemburgo, Holanda, Nova Zelândia, Noruega, Polônia, Portugal, Eslováquia, Eslovênia, Espanha, Suécia, Suíça, Reino Unido, EUA.
} 
Gráfico 1: Evolução da participação das exportações chinesas segundo tipo de tecnologia de 2001 a 2014

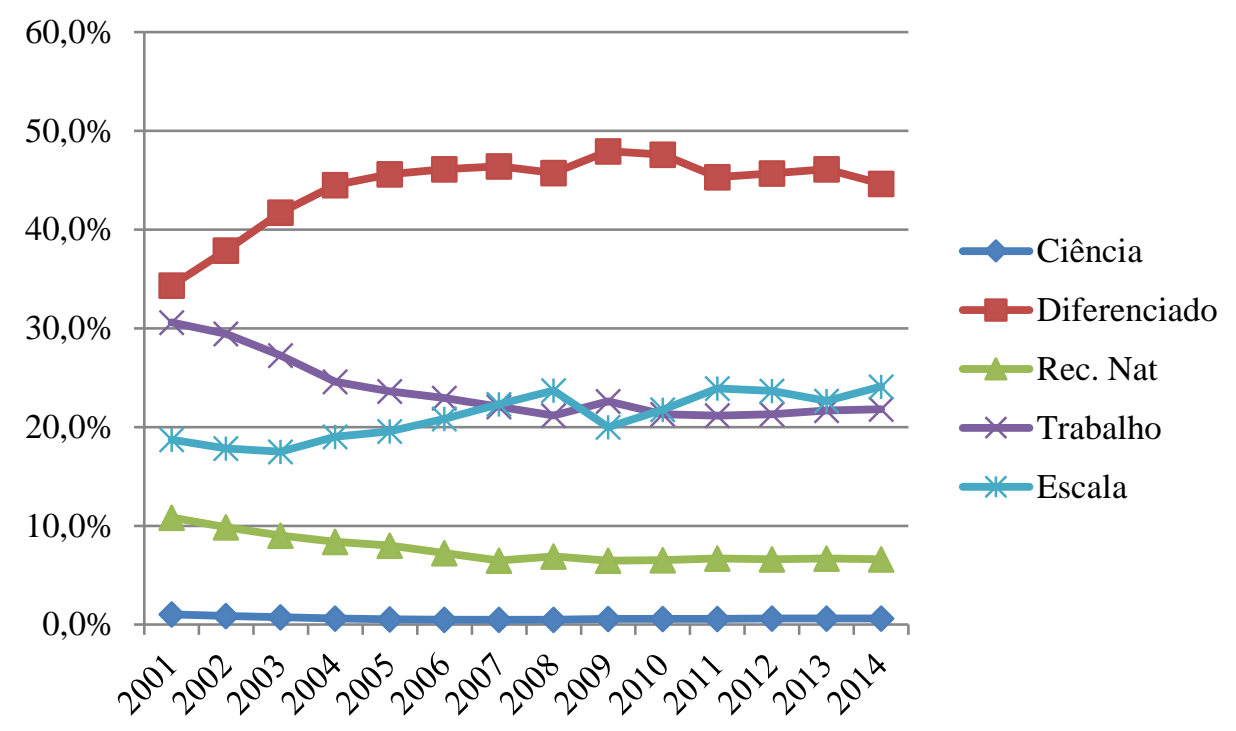

Fonte: COMTRADE ${ }^{6}$, 2015. Elaboração própria.

Esse movimento é mais facilmente percebido pelo Gráfico 2, que compreende a classificação por tecnologia dos 10 setores mais exportados pela China para os anos de 2001 e 2014, correspondendo a $62 \%$ e $67 \%$ de toda a exportação chinesa, respectivamente. $\mathrm{O}$ que se pode perceber é uma considerável mudança da pauta exportadora chinesa, com perda de participação de setores intensivos recursos naturais, que se tornou inexistente em 2014 ${ }^{7}$. Além disso, há um aumento significativo em setores diferenciado e intensivos em escala, de 12,7 pp e 8,4 pp, respectivamente. Já os setores intensivos em trabalho perderam quase metade da participação, com 12,45 pp a menos.

Gráfico 2: Participação na exportação dos dez principais setores chineses, por tecnologia, para os anos de 2001 (A) e 2014 (B)

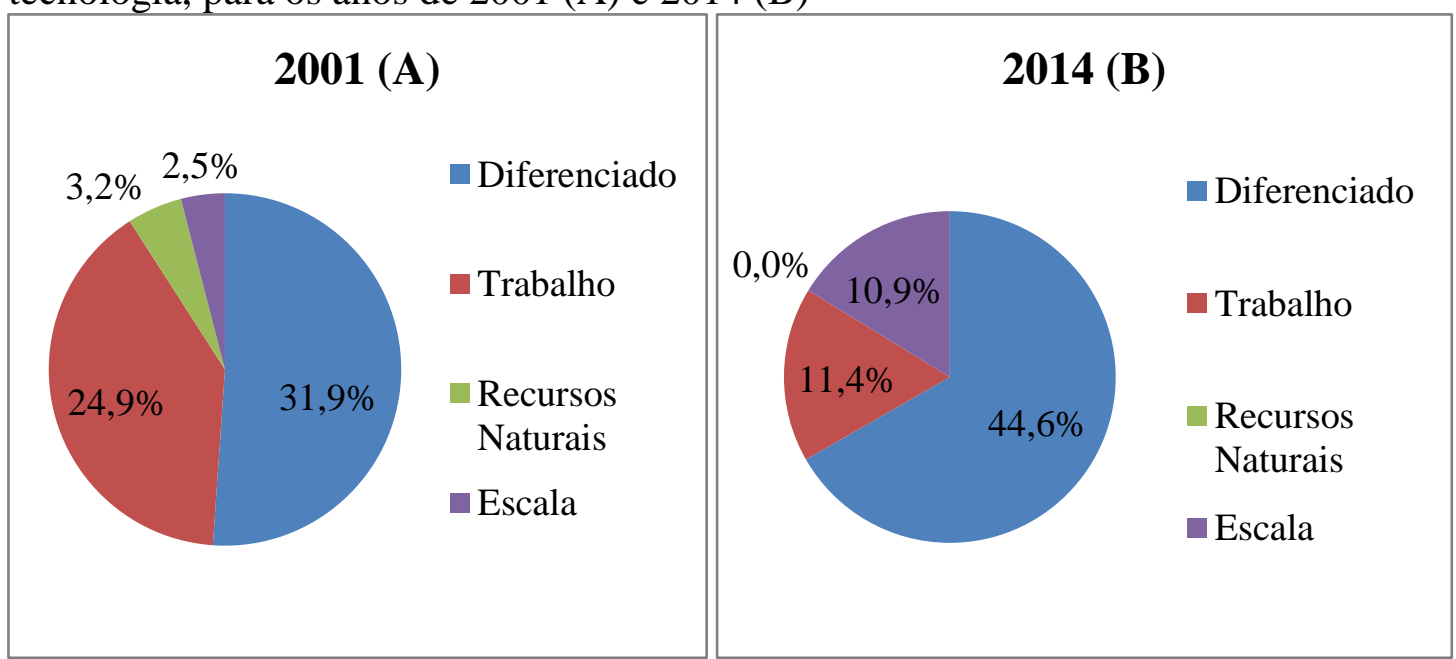

Fonte: COMTRADE, 2015. Elaboração própria.

${ }^{6}$ Comtrade é um repositório de estatísticas oficiais de comércio internacional e tabelas analíticas.

${ }^{7}$ Em 2011, havia um único setor pertencente a recursos naturais: 27 - Combustíveis minerais, petróleo e produtos de destilação, etc. 
No que diz respeito a economia americana há uma diminuição da participação das exportações de bens intensivos em tecnologia como pode ser visto no Gráfico 3. Com isso, infere-se que EUA e China se aproximaram quanto ao patamar de participação de setores diferenciado e baseados em ciência, que são setores intensivos em tecnologia. No entanto, ressalta-se que embora tenha havido uma diminuição significativa na exportação de bens em setor diferenciado, os EUA pouco mudaram sua pauta exportadora de 2001 a 2013. Sendo assim, os 10 setores mais exportados $^{8}$ são praticamente os mesmos, mudando apenas de posição.

Gráfico 3: Evolução da participação das exportações americanas, segundo tipo de tecnologia, de 2001 a 2014

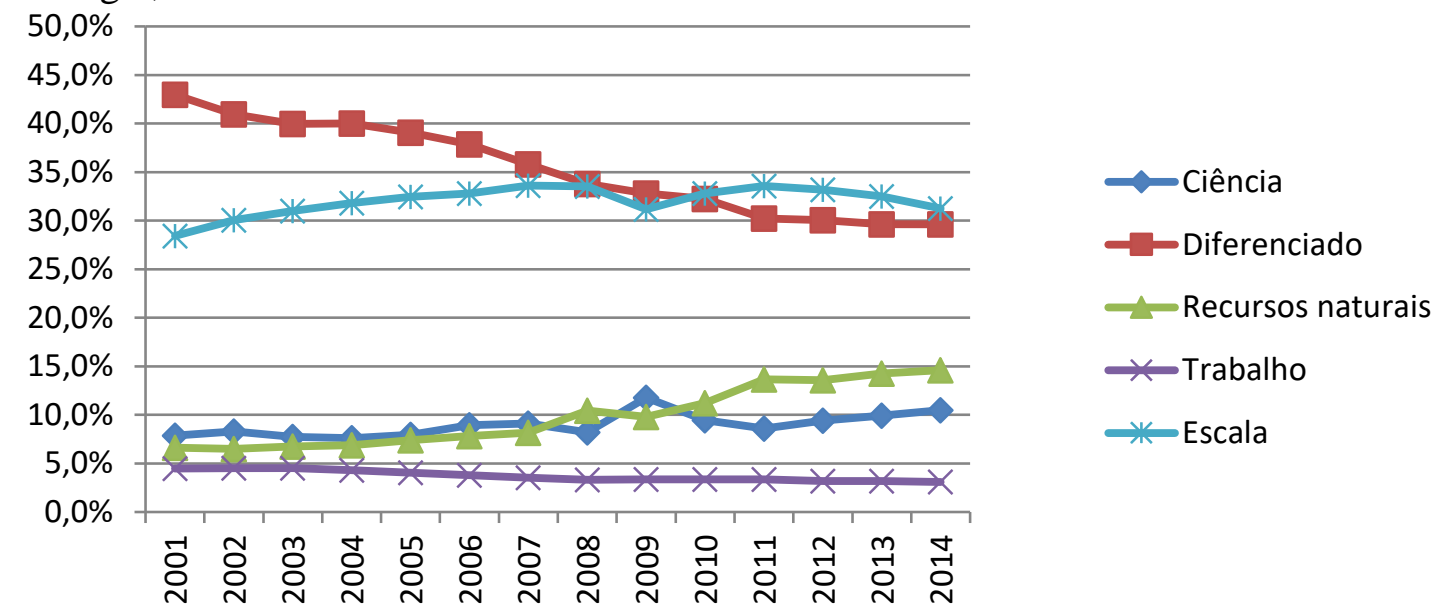

Fonte: COMTRADE, 2015. Elaboração própria.

Por fim, o Gráfico 4 apresenta a evolução do saldo comercial dos EUA e da China. Nota-se que a China apresenta um aumento do saldo em praticamente todos os tipos de tecnologia, com exceção dos bens baseados em ciência. Já os EUA mostraramse deficitário em todas as tecnologias, porém superavitário na tecnologia baseada em ciência.

884 - Fabricação de máquinas, reatores nucleares, caldeiras, etc; 85 - Fabricação de equipamentos e aparelhos elétricos; 87 - Veículos (Exceto trens e outros de linha férrea); 88 - Fabricação de aeronaves e componentes; 90 - Fabricação de instrumentos e materiais médicos, artigos ópticos; 39 Fabricação de plásticos e derivados; 71 - Fabricação de joalheria, bijuteria e semelhantes; 27 Combustíveis fósseis, petróleo, produtos destilados, etc.; 30 - Fabricação de produtos farmacêuticos. 
Gráfico 4: Evolução do saldo comercial, EUA e China, segundo tecnologia de 2001 a 2014 (em US\$ milhões)

EUA

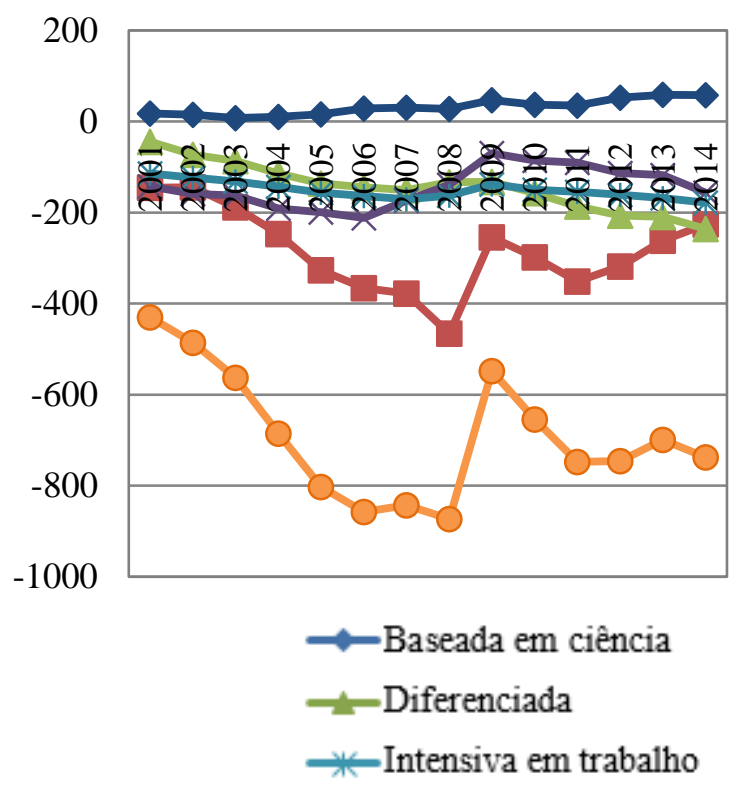

China

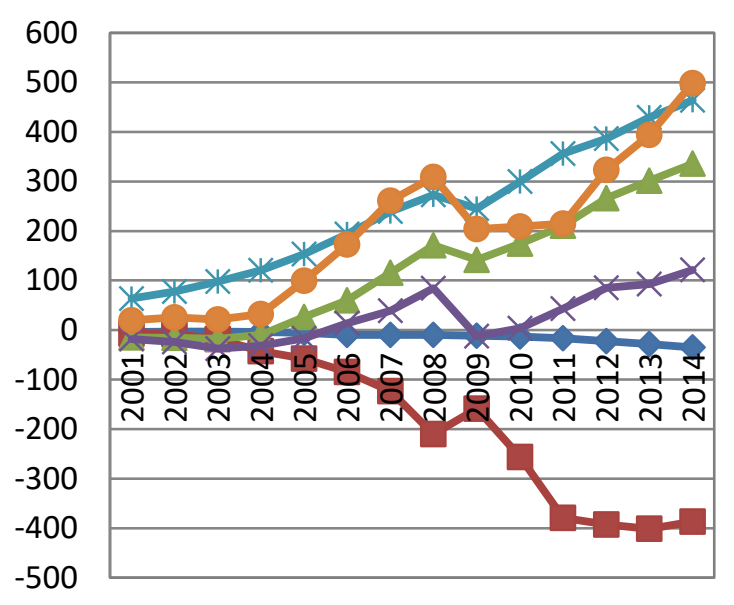

- - Baseada em recursos naturais

Intensiva em escala

Total

Fonte: COMTRADE, 2015. Elaboração própria.

$\mathrm{O}$ aumento do déficit do setor baseado em ciência indica que o processo de industrialização da China ainda apresenta fragilidades, tendo em vista que este tipo de tecnologia está associado ao desenvolvimento da pesquisa de ponta. Nesse aspecto, observa-se que o saldo americano nesta tecnologia é superavitário, que é um reflexo do esforço do país em ampliar a pesquisa e desenvolvimento somado a capacidade do mesmo em se concentrar nas principais atividades na rede global de produção. Além disso, a China apresenta baixo volume de comercialização nessa tecnologia quando comparada aos EUA. Dessa forma, tem-se aqui um processo de industrialização que caminha para a produção de produtos mais nobres na cadeia produtiva, mas que ainda está em construção.

Portanto, é possível verificar que existem alguns pontos em comum entre o comércio internacional da China e dos EUA. Ambos os países parecem convergir para patamares semelhantes de participação com relação aos setores mais intensivos em tecnologia. Além disso, embora a China ainda apresente uma participação de setores intensivos em trabalho, percebe-se um movimento de queda no share de tais produtos. Com isso, associado aos demais indicadores avaliados, nota-se um processo de sofisticação das exportações e diminuição da importância de dos bens intensivos em trabalho.

De forma geral, “(...) a China melhorou sua eficiência produtiva e está avançando na construção de capacidades tecnológicas, desenvolvendo uma indústria de alta tecnologia e consolidando sua posição em tais setores no mercado internacional" (CUNHA E XAVIER, 2010).

\subsection{Produção Industrial}

Ao observar os dados relacionados a comércio indaga-se a respeito do processo da sofisticação da produção industrial chinesa. Há autores como Lardy (2004) que propõe que a China exporta conteúdo tecnológico, porém nos elos menos nobres da cadeia que tende a agregar pouco valor, ou seja, o país serviria mais como uma 
plataforma de exportação. Por outro lado, autores como Rodrik (2006) e Sarti e Hiratuka (2010) apontam para mudança na sofisticação da produção chinesa. Com isso, é preciso verificar se houve aumento do conteúdo tecnológico produzido pela indústria local chinesa. Dessa maneira, a primeira análise compreende avaliar se houve um aumento da participação do valor da manufatura chinesa em relação aos outros países.

Gráfico 5: Evolução participação $\mathrm{MVA}^{9}$ no total mundial - China, EUA, Industrializados, Economias Emergentes (excluindo China) e Economias Emergentes incluindo China (1990 a 2012)

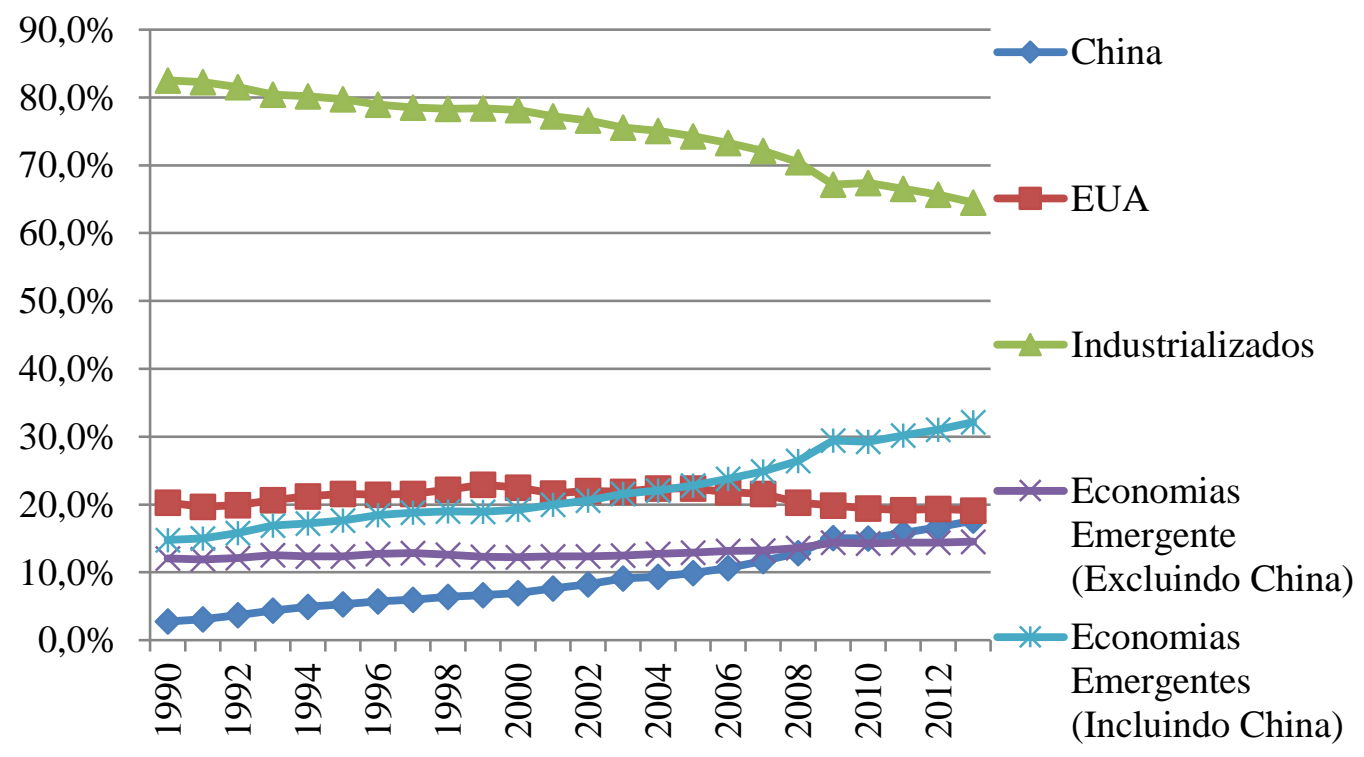

Fonte: UNIDO, 2013. Elaboração própria.

A partir do Gráfico 5, pode-se perceber que ainda que os países industrializados respondam, em 2012, por quase $60 \%$ de todo o valor adicionado da indústria mundial, essa parcela caiu significativamente, pois correspondia a 80\%, em 1990. Além disso, também é possível dizer que há uma convergência de valores com relação ao valor adicionado industrial pelos EUA e pela China.

Em 1990, o valor adicionado da indústria chinesa correspondia a praticamente zero do total mundial, enquanto o valor adicionado da indústria americana era de cerca de $20 \%$. Já em 2012, os valores convergem para cerca de $20 \%$. Ressalta-se também que há uma participação crescente para "economias emergentes" ao incluir a China. Ao excluí-la, observa-se, por outro lado, uma constância da parcela do valor adicionado da indústria.

Além de apresentar o aumento da participação da indústria chinesa no mundo, avalia-se pelo Gráfico 6, através da evolução da participação do valor adicionado chinês, que essa indústria sofreu uma mudança na sua composição.

\footnotetext{
${ }^{9}$ Valor Adicionado na manufatura..
} 
Gráfico 6: Evolução da participação do valor adicionado chinês, segundo tipo de tecnologia - 1980 a $2007^{10}$

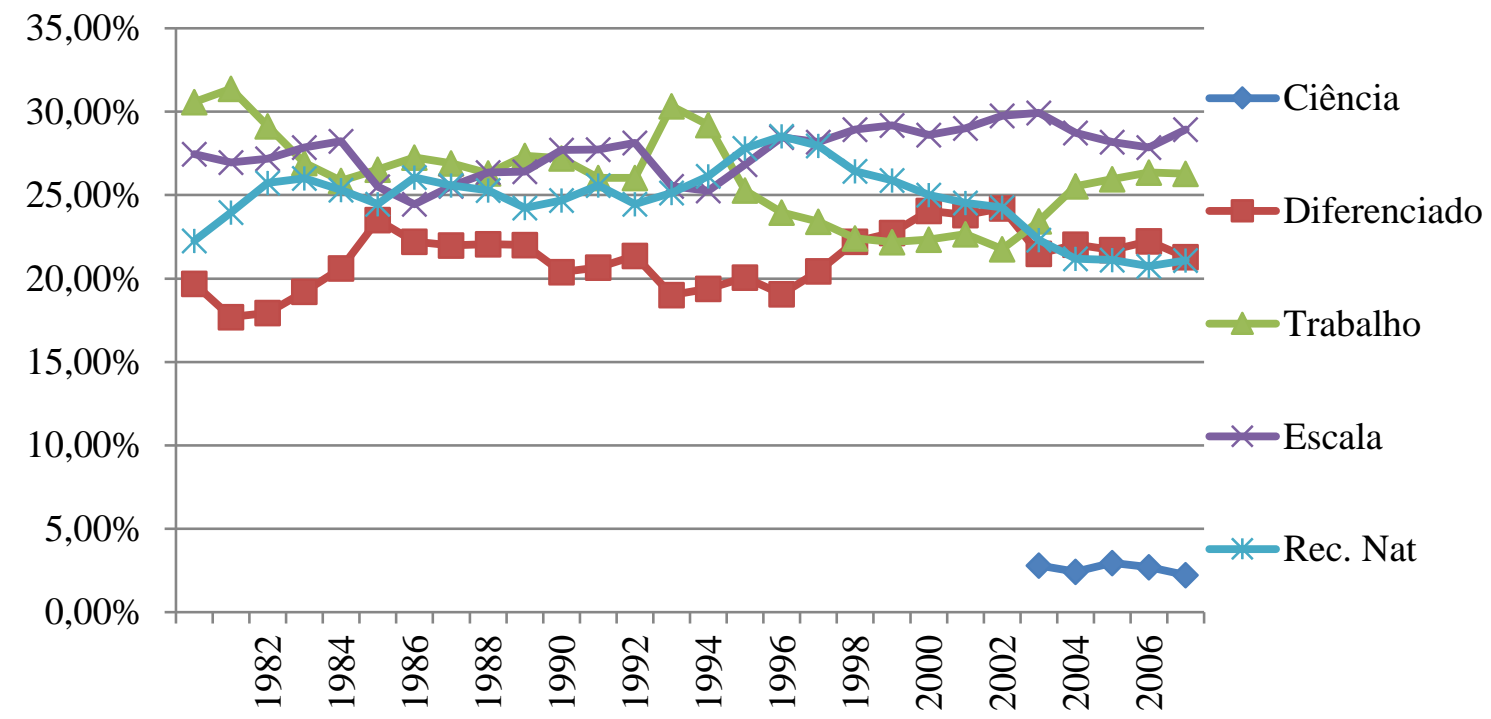

Fonte: UNIDO, 2013. Elaboração própria.

Nota-se pelo Gráfico 6 que a China apresentava, em 1980, 52,8\% de todo seu valor adicionado concentrado nos setores de trabalho e recursos naturais. Em 2007, os mesmos setores representaram 47,4\% do total adicionado. Dessa forma, percebe-se que a maior parte do valor adicionado passou a ser de setores ligados a ciência, diferenciado e escala.

Avaliando a mudança de composição dos setores que mais contribuíram para o processo em cada tecnologia, observa-se: (i) nos setores intensivos em trabalho o que mais perdeu participação foi o 17 (Fabricação de produtos têxteis), que em 1980, representava $15,1 \%$ e em, 2007, 5,2\%; (ii) nos setores intensivo em recursos naturais, dois setores registraram queda de sua participação, o setor 16 (Fabricação de produtos do fumo) que caiu de $4 \%$ para $3 \%$ e o setor 23 (Coque, produtos de petróleo refinado) de 4,9\% para 3,1\%; (iii) nos setores diferenciados, embora tenha havido queda da participação do setor 29 (Fabricação de máquinas e equipamentos), todos os demais cresceram; (iv) nos setores baseados em ciência, nota-se que o setor 30 (Fabricação de máquinas e equipamentos para escritório) apresentou crescimento; (v) nos setores intensivos em escala, dois apresentaram crescimento, o setor 34 (Fabricação de veículos automotores, trailers, semi-trailers) que elevou sua participação de $3,4 \%$ para $5,2 \%$, e o setor 35 (Outros equipamentos de transporte) que foi de $0 \%$ para 1,9\%.

O Gráfico 7 mostra que a economia americana demonstra uma certa estabilidade na produção industrial. Porém, destaca-se uma diminuição na participação da produção diferenciada, enquanto há um aumento da mesma para a China. Também é importante ressaltar que a economia americana apresenta uma participação superior para a produção de bens intensivos em escala. Contudo, reitera-se que a economia chinesa apresentou tendência de crescimento da participação desta tecnologia de $25 \%$ para $30 \%$.

${ }^{10}$ Os dados que dizem respeito a valor adicionado para China estão disponíveis somente até 
Gráfico 71: Evolução da participação do valor adicionado americano, segundo tipo de tecnologia - 1980 a $2007^{11}$

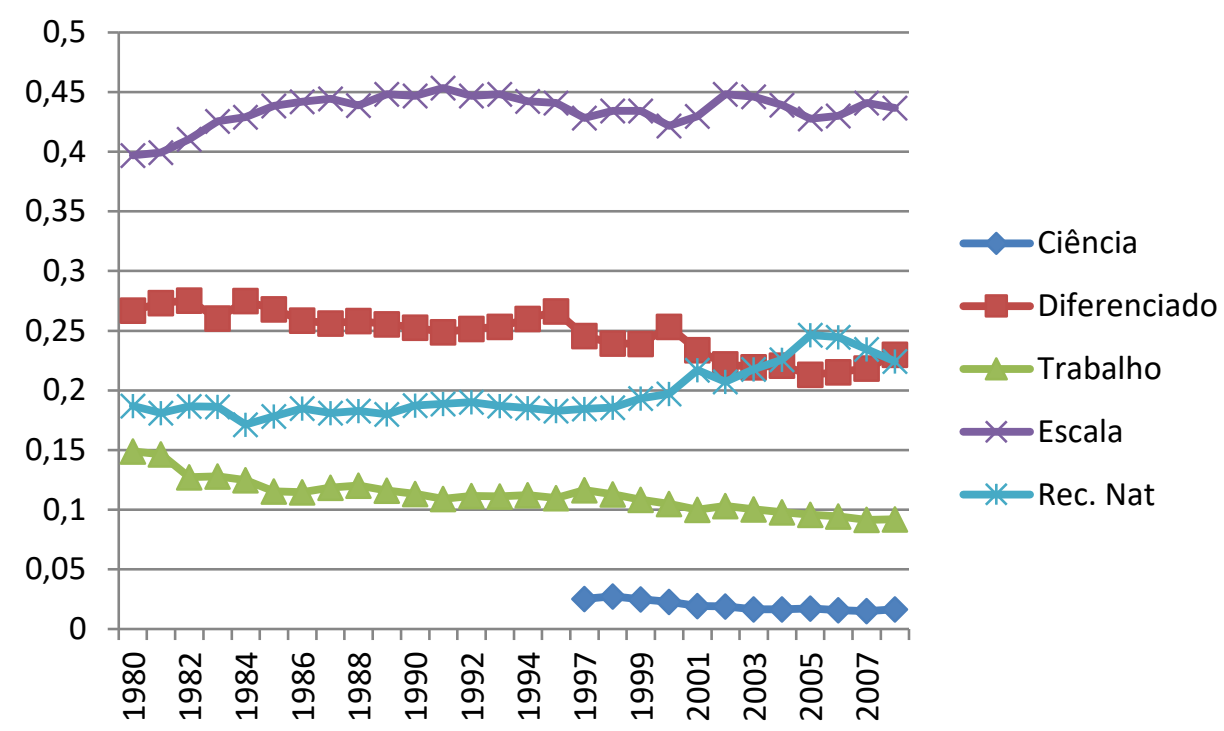

Fonte: UNIDO, 2013. Elaboração própria.

Ao considerar uma comparação entre as duas economias, observa-se que ambas apresentam patamares próximos de participação dos setores mais intensivos em tecnologia, ou seja, setores intensivos em ciência e diferenciados. A diferença entre os países, contudo, é que setores intensivos em trabalho ainda apresentam uma participação relevante para a economia chinesa e escala, para os EUA.

\section{Salários e produtividade}

Pinto apud Nogueira (2011) analisam que os salários na China apresentam uma trajetória ascendente semelhante à dos países que realizaram catching up tecnológico. Porém, argumenta-se que os ganhos de produtividade são maiores que o aumento da massa salarial. Logo, a competitividade via preços da indústria chinesa estaria mantida em relação aos outros países. Além disso, ressalta-se Nonnenberg (2008) que analisa não ser possível observar aumentos salariais substanciais na China se comparados aos níveis de salários internacionais.

Por outro lado, há autores que argumentam que existe um aumento de produtividade menor que os salários. Li et al (2012) apontam que de 1982 até 1997, os ganhos de produtividade são maiores que os aumentos salariais, porém essa situação se inverte no período posterior. Juntamente a eles, Cintra e Pinto (2015) afirmam que a partir dos anos 2000 os custos relacionados aos salários cresceram a taxas maiores que as taxas de aumento de produtividade.

${ }^{11}$ Não há dados para o ano de 1996. 
Gráfico 8: Taxa de crescimento da massa salarial chinesa (valores anuais) - 1980 a $2007^{12}$ por tipo de tecnologia ${ }^{13}$

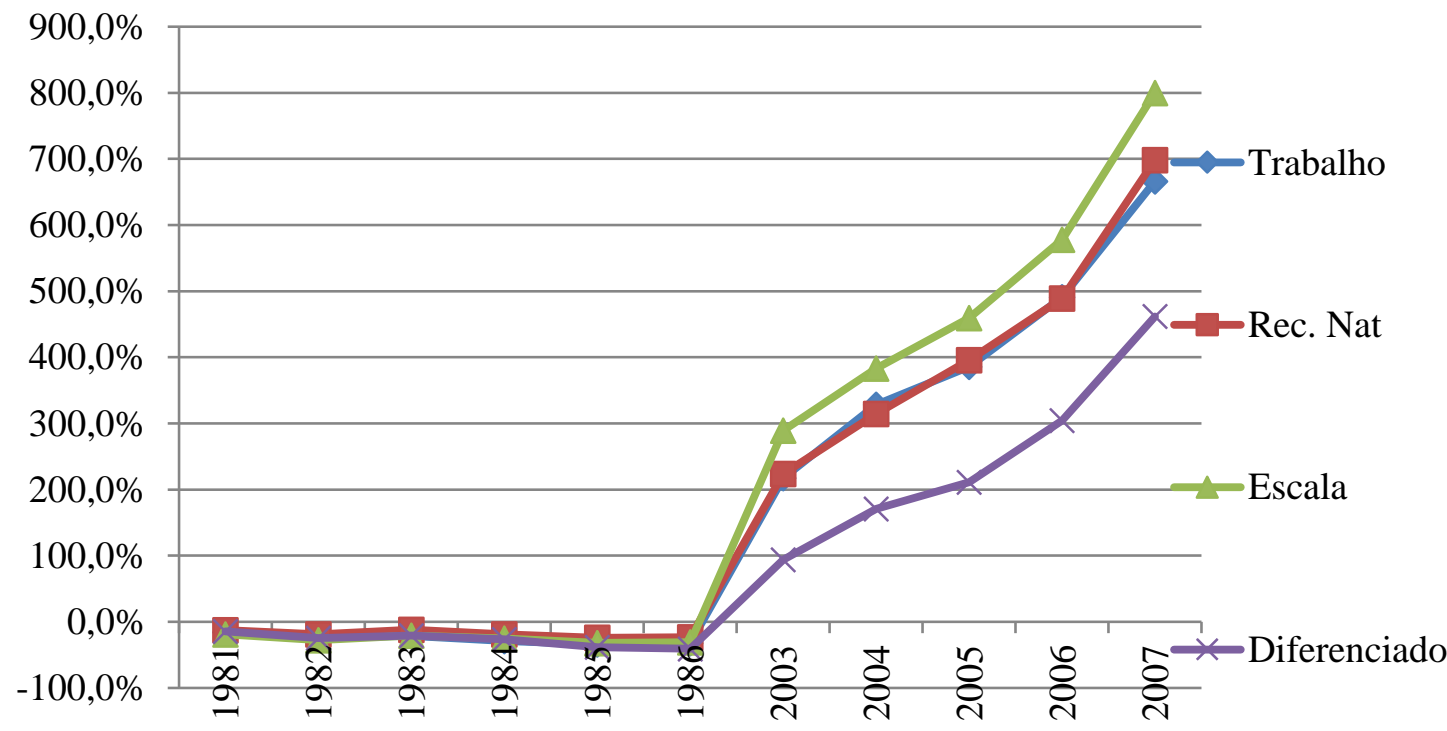

Fonte: UNIDO, 2013. Elaboração própria.

Ao verificar o Gráfico 8, tendo como base para o cálculo o ano de 1980, os salários tiveram uma trajetória ascendente, chegando a uma taxa de crescimento de $800 \%$ em relação ao ano de 1980, para os bens intensivos em escala. Uma análise dos setores industriais também permite afirmar que os salários médios cresceram em todas as tecnologias no período entre 2003 e 2010 , apresentando crescimento ${ }^{14}$ de $321 \%$ no setor intensivo em recursos naturais, $288 \%$ no setor de trabalho, $276 \%$ no setor intensivo em escala, $241 \%$ no setor diferenciado e $230 \%$ no setor baseado em ciência.

Além disso, avalia-se que o emprego industrial também aumentou em todas as tecnologias, no período analisado, com crescimento de $133 \%$ no setor intensivo em ciência, $114 \%$ no setor diferenciado, $55 \%$ no setor baseado em escala, $55 \%$ no setor baseado em escala e $44 \%$ no setor intensivo em trabalho, que permite afirmar que o crescimento da massa salarial é resultado do aumento combinado dos salários e do emprego gerado pela indústria.

Ainda no que diz respeito ao emprego, destaca-se que o crescimento da geração de empregos na tecnologia baseada em ciência acompanhada pela diferenciada apresentaram maior taxa de crescimento, porém estes setores não foram os maiores empregadores absolutos. Na verdade, nota-se que o setor baseado em ciência ainda era o menor empregador em termos absolutos em 2010. Por outro lado, o setor diferenciado está entre os setores que mais empregam na economia, de forma que quase 20 milhões

${ }^{12}$ Não há dados para os anos entre 1986 e 2003. Além disso, destaca-se que todos os valores de valor adicionado e salários foram deflacionados pelo deflator do PIB americano, tanto para os dados chineses quanto para os dados americanos. Este é o mesmo procedimento adotado em Li et al (2012). Segundo os autores, é uma maneira interessante de medir o quanto os consumidores americanos pagam pelo trabalho embutido nos bens chineses. O deflator foi obtido pelo indicador do World Bank (2015).

${ }^{13} \mathrm{O}$ dado da tecnologia baseada em ciência é correspondente ao setor 30 - Máquinas para escritório e equipamentos de informática - e não apresentou informações para o ano de 1980, o que impossibilitou realizar a taxa de crescimento, dado o ano base para o cálculo é 1980.

${ }^{14}$ Para avaliação tanto do crescimento do salário quanto do emprego, tomou-se o ano de 2003 como base $(2003=100)$. 
de chineses em 2010 estavam empregados em setores produtores de máquinas, máquinas elétricas \& aparelhos, rádio, televisão e equipamentos de comunicação.

Com o processo de industrialização e estímulo ao desenvolvimento de setores com tecnologias mais dinâmicas, propiciou-se uma maior geração de emprego nesses setores que permite inferir a respeito de mudanças qualitativas na mão-de-obra chinesa. A avaliação da qualificação do trabalho condiz com Nonnemberg (2014) ao analisar que as mudanças na pauta produtiva chinesa são resultados de esforços em inovação e qualificação da mão-de-obra. Medeiros (2008) também que destaca o papel do aumento dos investimentos na qualificação da mão-de-obra como vetor importante na mudança da política industrial e tecnológica que propiciou a inovação ser uma estratégia produtiva.

No entanto, destaca-se, de acordo com Gouveia (2012), que o aumento salarial faz parte de uma política governamental de fomento ao consumo buscando endogeneizar o crescimento econômico. Ou seja, para além de apenas representar um reflexo do processo de catching up, o aumento salarial reflete uma estratégia que visa a construção de uma nova etapa do modelo de desenvolvimento chinês. Nesse aspecto, reitera-se Medeiros (2010) ao apontar que "também existe uma pressão dentro do próprio partido comunista, para que haja um crescimento mais equilibrado no qual o consumo fosse componente protagonista". (MEDEIROS, 2010).

Enquanto isso, a economia americana apresenta queda dos salários, como demonstra o Gráfico 9, tendo o ano 1980, como base fixa, sendo que o único segmento que apresentou aumento foi o de recursos naturais. Vale ressaltar que, em alguma medida, os Gráficos 8 e 9 refletem as mudanças descritas, anteriormente, pelo fluxo de investimento direto estrangeiro dos EUA para a China. As principais empresas americanas redirecionaram seu investimento, fechando inclusive algumas fábricas em território nacional para produzir em território chinês em busca de menores custos de produção. Este processo se deu mais facilmente em produções cujas etapas pudessem ser mais facilmente fracionadas e padronizadas, como as indústrias de têxtil e vestuário e eletrônica. Este movimento se revela pelo Gráfico 9, cujas maiores quedas salariais se deram nas tecnologias intensivas em trabalho e diferenciada. Para a produção de bens diferenciados, conta-se em grande parte com o setor ligado a eletrônicos, enquanto para o tipo de tecnologia intensiva em trabalho, abarcam-se os setores de têxtil e vestuário.

Dessa forma, percebe-se que o gráfico reflete o deslocamento de unidades fabris dos EUA para a China, como já foi descrito previamente, que impacta no desaparecimento do emprego industrial nos EUA. Existem estudos, como de David, Dorn e Hanson (2013), que apontam para uma relação entre o aumento das importações chinesas e a diminuição do emprego americano. Os autores demonstram que a exposição dos EUA às importações chinesas trouxe aumento do desemprego, diminuição da participação da força de trabalho, além de salários menores. 
Gráfico 9: Taxa de crescimento da massa salarial americana (valor corrente) (19802007) por tipo de tecnologia

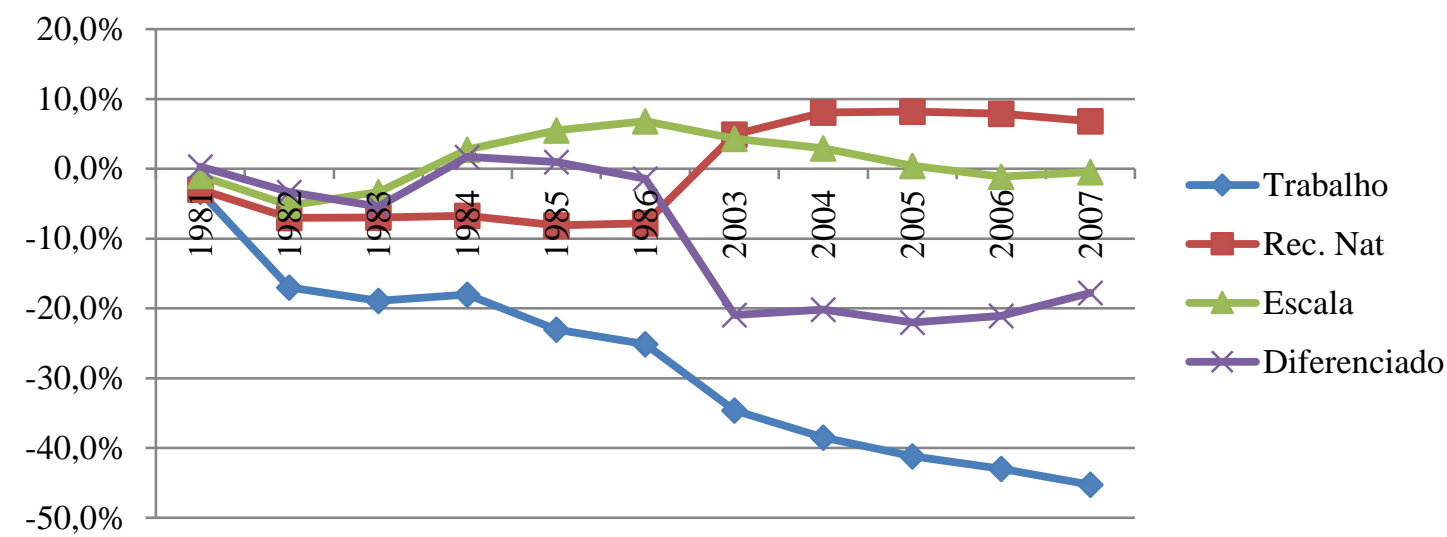

Fonte: UNIDO, 2013. Elaboração própria.

Quanto à comparação entre crescimento de produtividade e salários, pode-se verificar que a os dados corroboram a literatura abordada previamente. O Gráfico 10 demonstra um crescimento exponencial da produtividade, porém este não superou o aumento de salários ${ }^{15}$, tendo como base fixa o ano de 1980. O tipo de tecnologia diferenciado obteve o menor aumento salarial (400\%), em 2007, e apresentou o maior aumento de produtividade $(250 \%)$ de todos os tipos de tecnologia. Portanto, verifica-se, de modo geral na economia chinesa, um aumento salarial superior aos ganhos de produtividade.

Gráfico 10: Taxa de crescimento da produtividade chinesa, segundo tecnologia, em porcentagem - 1980 a 2007

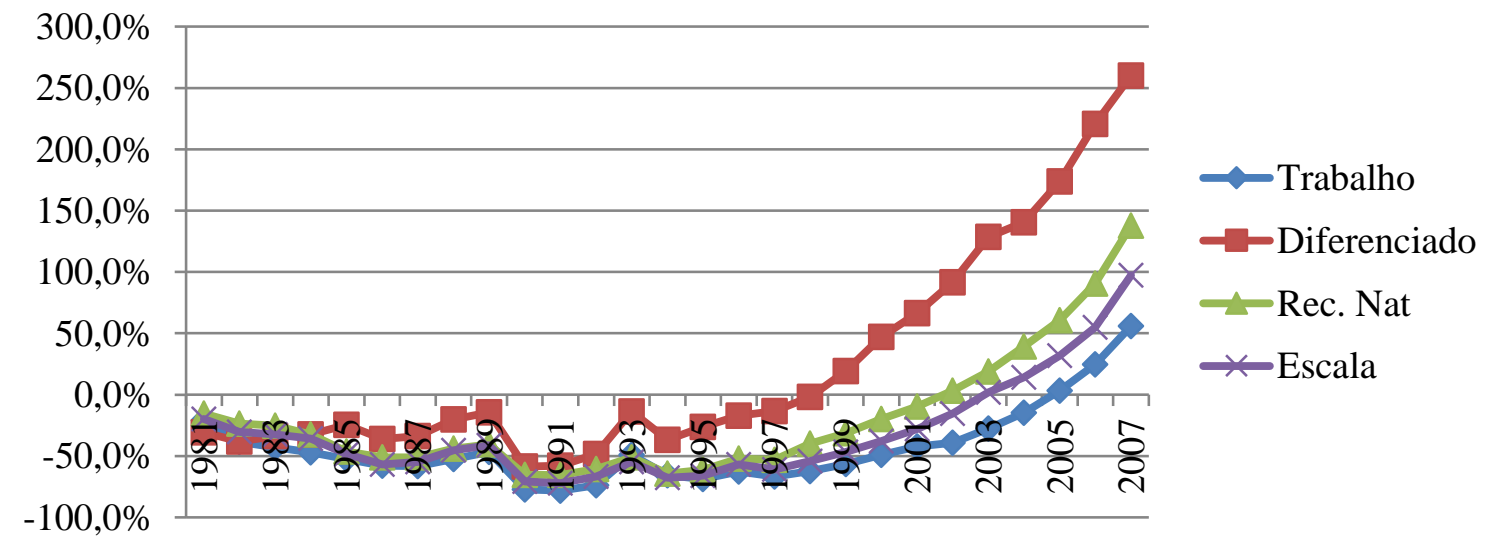

Fonte: UNIDO, 2013. Elaboração própria.

A economia americana, por sua vez, apresenta um movimento constante de ganhos de produtividade, como pode ser visto no Gráfico 11, juntamente a quedas no crescimento dos salários reais, tendo como base fixa o ano de 1980. A tecnologia que apresentou ganhos salariais positivos e terminou com $10 \%$ de aumento salarial, apresentou, em 2007, de pouco mais de $60 \%$ de aumento da produtividade. Dessa forma, a economia americana tem a sua competitividade garantida, com ganhos de produtividade maiores que os incrementos salariais.

${ }^{15} \mathrm{O}$ crescimento do salário foi inferior ao da produtividade mesmo quando avaliado o salário médio (massa salarial dividida pelo número de pessoas ocupadas) deflacionado pelo índice de preço ao consumidor, obtidos através do China Statistical Yearbook. 
Gráfico 11: Taxa de crescimento da produtividade americana, segundo tipo de tecnologia, em porcentagem - 1980 a 2007

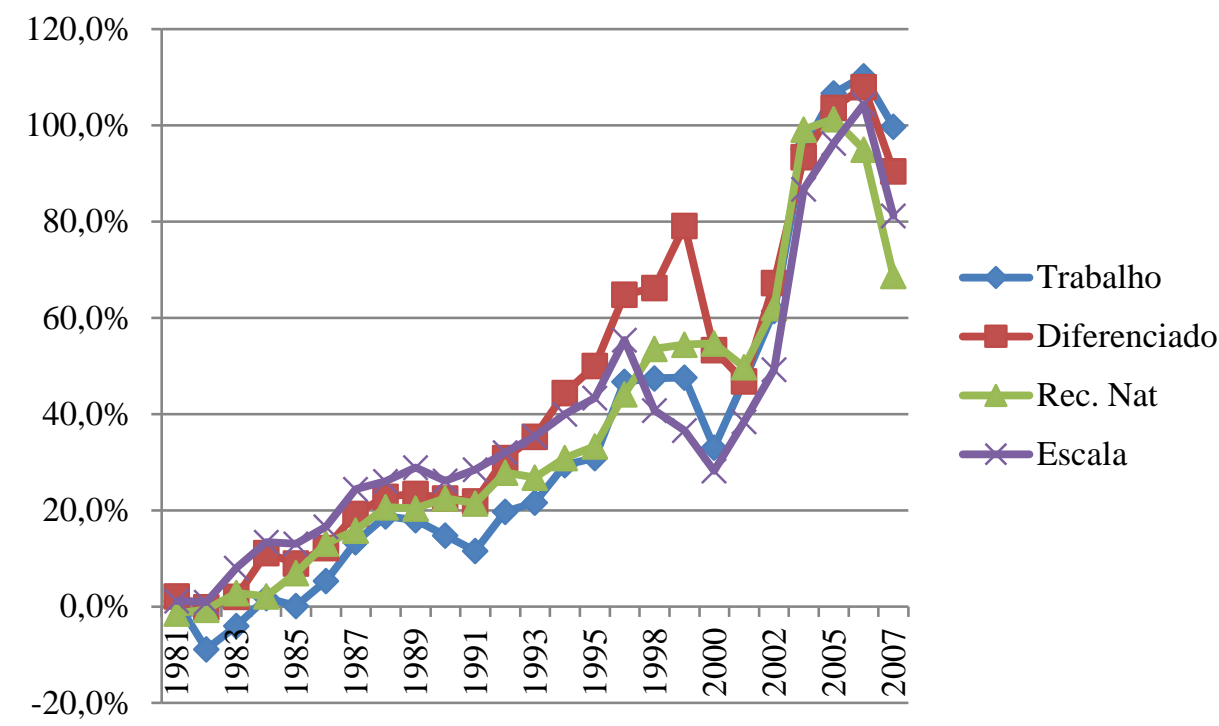

Fonte: UNIDO, 2013. Elaboração própria.

Percebe-se então que os dois movimentos se solidificam na sociedade chinesa, ou seja, tanto o movimento de mudança na estrutura produtiva, com maior sofisticação da sua produção, quanto o aumento salarial. Este último sendo superior ao incremento de produtividade. Portanto, ambos podem exercer movimento de aumento de preços de bens industriais exportados pela China. No entanto, destaca-se, com relação ao crescimento da massa salarial, que apesar da sua participação no valor adicionado para todos os tipos de tecnologia ter crescido ao longo dos anos analisados, esta não ultrapassou $20 \%$ do VA o que permite afirmar que a lucratividade não tem sido comprometida pelo aumento da variável ${ }^{16}$. Essa afirmação é possibilitada pela definição da OCDE (2015) de que o valor adicionado reflete a contribuição do capital e do trabalho para a produção. ${ }^{17}$

\section{Evolução dos preços relativos de exportações industriais chinesas}

Devido ao movimento na estrutura produtiva, esperava-se que os preços chineses em diferenciado, escala e ciência aumentassem, pois, como apontado Schott (2004) os valores unitários das exportações estão correlacionados positivamente com a intensidade de capital utilizado em sua produção. Por outro lado, os segmentos menos intensivos em tecnologia, como trabalho e recursos naturais, também apresentariam um aumento dos preços, porém por motivos diferentes. Neste caso, os salários exerceriam um papel importante na composição do preço, o que faria com que houvesse um aumento do preço dos bens exportados.

Dessa maneira, realizou-se a construção do indicador de preços de exportação dos produtos industriais a partir dos dados da CEPII ${ }^{18}$ (Baci). A proxy de preços

${ }^{16}$ Faz-se uma ressalva que esses dados foram calculados a partir da UNIDO, 2013.

${ }^{17}$ Nesse sentido, destaca-se que o crescimento da massa salarial industrial urbana, deflacionada pelo índice de preço do consumidor, entre 2003 e 2015 foi de 4,36 enquanto o crescimento da lucratividade na indústria, deflacionada pelo índice de preço do produtor, para o mesmo período foi de 5,62. Esses dados foram obtidos através do site de estatística da China e reforçam que o movimento de aumento dos salários não comprometeu o crescimento da lucratividade.

18 CEPII é um centro de pesquisa francês em economia internacional que produz estudos, pesquisas, bancos de dados e análises sobre a economia mundial e sua evolução. 
utilizada foram os chamados Trade Unit Value (TUV) ${ }^{19}$, que conta com mais de 5000 produtos, por ano, em até 6 dígitos de desagregação, baseados no sistema harmônico.

O indicador utilizado é construído com base nas importações americanas da China e outros parceiros, durante os anos de 2001, 2007 e 2013. Para a construção do índice, foram elencados os principais parceiros dos EUA, segundo tecnologia, ou seja, os países que mais exportaram, em valor, para os EUA, para cada tipo de tecnologia. Os dados de produtos foram compatibilizados entre os países, de modo que foram comparados os preços dos produtos comuns para cada um dos países.

Dessa forma, dentro de uma mesma tecnologia, são comparados os preços dos produtos comuns para China e outros parceiros comerciais dos EUA para um determinado ano. O índice representa uma comparação relativa entre os países, a partir de um diferencial de preços, dado pela equação abaixo:

$$
\mathrm{P}=\sum_{1}^{i}\left\{\left[\left(P_{t}^{i c} / P_{t}^{i p}\right)-1\right] * w_{t}^{i c}\right\}
$$

O índice se dá pela divisão de $P_{t}^{i c}$, o preço do produto i, no país China, no ano t, pelo preço de $P_{t}^{i p} \cdot$, ou seja, o preço do mesmo produto i, no ano t, em outro país (p), escolhido por ser o mais importante exportador para o mercado americano em determinada tecnologia. Após a divisão dos preços, aplica-se o diferencial, subtraindo um. Posteriormente, para cada bem i, é calculada a sua importância na pauta exportadora chinesa ${ }^{20}$, dada por $w_{t}^{i c}$.

$$
w_{t}^{i c}=X_{t}^{i c} / X_{t}^{c}
$$

A ponderação dada por $w_{t}^{i c}$ é obtida pela razão entre $X_{t}^{i c}$, ou seja, o valor do produto i, para o ano t, na pauta de exportação da China para os EUA, por $X_{t}^{c}$, que é o valor das exportações de produtos presentes em determinada tecnologia. Destaca-se que os produtos que compõe a pauta ponderadora de importação dos EUA da China foram organizados em ordem decrescente para o ano de 2013. Essa ponderação privilegia os produtos que compõe pautas recentes.

A ponderação visa evitar que produtos que não fossem relevantes à exportação chinesa tivessem peso significativo na construção do indicador. Por exemplo, se existe um aumento de preço relativo para um determinado produto, logo, há um aumento de preços relativos do índice e, como um todo, para uma determinada tecnologia. Porém, se este mesmo produto é insignificante para a pauta exportadora chinesa, no mercado americano, o aumento de preço desse produto não pode ser entendido como diminuição da competitividade.

A principal ideia do índice é que o movimento do diferencial de preços seja capaz de captar alguma diferença de competitividade das exportações chinesas com de outro parceiro comercial dos EUA para o mercado americano. A construção dos índices se dá, primeiramente, pela compatibilização de produtos exportados pela China e por outro parceiro, em determinada tecnologia, para um ano especifico. Isso permite a obtenção dos produtos em comum na exportação chinesa e do país parceiro. Para que possa ser realizada a ponderação, é necessário que existam produtos comum à lista dos 500 produtos mais exportados, pela China para os EUA, e os produtos comuns à China

${ }^{19} \mathrm{O}$ CIF (Cost of Insurance and Freight) é determinado pela declaração do importador. Inclui todos os custos de comércio (exceto tarifas e taxas domésticas). O FOB (Free on board) é uma proxy para preços de comércio, baseado nas declarações dos exportadores. Não incluem custos de comércio.

${ }^{20} \mathrm{O}$ intuito do trabalho é observar se há aumento dos preços chineses. Logo, é importante verificar se os produtos que sofreram aumento de preços são produtos importantes para a pauta de exportação chinesa. Dessa forma, os pesos são calculados para cada ano t, para cada bem i, a partir dos dados presentes no Trademap. 
e ao parceiro. Dessa forma, os produtos que serão utilizados na construção do indicador final são aqueles que fazem parte da intersecção entre os 500 produtos mais exportados e os produtos comuns ao parceiro comercial e à China.

Explica-se, em termos de interpretação do índice, que um valor negativo representa que o preço do parceiro comercial é maior que o preço chinês, ou seja, neste caso a China não estaria perdendo sua competitividade em termos de preço. Da mesma forma, um índice positivo indica um encarecimento do produto chinês frente ao parceiro comercial analisado. Porém, a avaliação relevante ao trabalho é o movimento do índice ao longo dos anos e não seu valor para um período em específico.

Os produtos comuns aos 500 produtos mais exportados, China e o parceiro comercial apresentam o valor das exportações para cada ano. A somatória de todos os valores de exportação para cada produto, em determinada tecnologia consiste em $X_{t}^{c}$. Logo, para cada produto i, é possível descobrir sua participação na pauta exportadora China-EUA.

A escolha dos parceiros foi realizada a partir dos dados do TradeMap ${ }^{21}$, ferramenta da COMTRADE, com os principais parceiros americanos. Os principais parceiros dos EUA são a China, Canadá e México, para o ano de 2013, cada qual para um segmento tecnológico, como pode ser visto na Tabela 1. Esta mostra além do principal parceiro comercial por tipo de tecnologia o diferencial de preços relativos entre a China e os parceiros comerciais. Por exemplo, para o ano de 2001 e para a tecnologia diferenciada, a China era 49,4\% mais barata que o México.

Tabela 1: Evolução do diferencial de preços entre China, Alemanha, Canadá e México, segundo tecnologia, para os anos de 2001, 2007 e 2013

\begin{tabular}{lllll}
\hline \multicolumn{1}{c}{ Tecnologia } & \multicolumn{1}{c}{ País } & \multicolumn{2}{c}{2001} & 2013 \\
\hline Diferenciado & México & $-49,40 \%$ & $-24,50 \%$ & $-37 \%$ \\
Escala & Canadá & $17,30 \%$ & $-36,80 \%$ & $-30,40 \%$ \\
Ciência & Alemanha & $-31,80 \%$ & $-63,6 \%$ & $-88,10 \%$ \\
Rec. Nat & Canadá & $-55,80 \%$ & $-51,20 \%$ & $-39,40 \%$ \\
Trabalho & México & $2,60 \%$ & $16,89 \%$ & $-7,40 \%$ \\
\hline
\end{tabular}

Fonte: CEPII, 2013. Elaboração própria.

Para análise dos resultados foram selecionados os três produtos que mais contribuíram para o diferencial de preço em cada ano e em cada tipo de tecnologia e também os três produtos que menos contribuíram para o resultado final. Dessa forma, busca-se além de identificar padrões, ao longo dos anos, de setores que contribuíram para o diferencial de preços final, identificar setores que eventualmente mudaram sua posição.

No que diz respeito à tecnologia baseada em ciência, percebe-se que o produto "Relógios de pulso, alimentados por bateria, com display ótico-eletrônico" apresenta um diferencial de preço da China em relação à Alemanha negativo para os três anos analisados, mostrando a competitividade via preço do país asiático neste produto. $\mathrm{O}$ produto "Peças de aeronave" também foi responsável pelo diferencial de preços negativo da China nos anos de 2001 e 2007. Em termos de setor, nota-se que o setor farmacêutico (30) apresentou maior contribuição para que a China fosse mais cara que a

${ }^{21}$ A base do TradeMap fornece - sob a forma de tabelas, gráficos e mapas - indicadores de desempenho de exportação, demanda internacional, mercados alternativos e mercados competitivos, bem como um diretório de empresas importadoras e exportadoras. Este cobre 220 países e territórios e 5300 produtos do Sistema Harmonizado. 
Alemanha enquanto o setor de relógios (91) contribui preponderantemente para que a China fosse mais barata que o país europeu.

Com relação à tecnologia diferenciada, percebe-se que o produto computador portátil contribuía para que a China fosse mais cara que o México em 2007, mas em 2013 o produto passou a ser o mais influente para que a China fosse mais barata que o país latino nessa tecnologia. Nesse aspecto, cabe resgatar Nonnenberg e Mesentir (2012) que ao avaliar a intensidade tecnológica das exportações da China ressalta que os ganhos em intensidade tecnológica da pauta exportadora do país entre 1980 e 2009 se deram principalmente no setor de computadores e de bens de telecomunicações, em que, segundo os autores, situam-se vantagens comparativas chinesas, que são crescentes para o país asiático e decrescentes para países desenvolvidos.

Outros produtos que merecem destaque são os de "Unidades de armazenamento de dados de computador" que ao longo dos anos analisados sempre contribuiu para que a China fosse mais barata que o México e o "Aparelho eletrotérmico doméstico" que, ao contrário, sempre contribuiu para que a China fosse mais cara que o México. De forma geral, nota-se que ao longo dos anos o setor "Maquinários, reatores nucelares e caldeiras" (84) colaborou para a China fosse mais barata que o país latino, enquanto o setor de "Equipamentos elétricos e eletrônicos" contribuiu mais para o país asiático fosse mais caro que o México.

Já para os setores intensivos em trabalho, nota-se que o produto "Assento com armação de metal" contribuía em 2007 para que a China fosse mais cara que o México, já em 2013, o mesmo produto contribuía para a China fosse mais barata. Essa tecnologia tem uma peculiaridade ao inverter de sinal ao longo dos anos analisados, ou seja, apresenta que a China tem se tornado mais competitiva via preços.

De forma geral, percebe-se que o setor de "Mobiliário, iluminação, sinais, construções pré-fabricadas" (94) apresentou produtos entre os que menos contribuíram para o resultado final. Quando a China não era competitiva nessa tecnologia, o setor era, e quando o país se tornou competitivo, o setor não contribuiu para o processo, ou seja, trata-se de um setor que a China perdeu competitividade. Por fim, observa-se que não é possível identificar padrões nesse tipo de tecnologia já que os produtos mais influentes da pauta (tanto os três mais influentes quanto os menos influentes) alternaram ao longo dos anos analisados.

Com relação à tecnologia baseada em escala, os produtos "De uso doméstico e artigos de higiene, de plásticos" e "Obras de plástico" sempre contribuíram para que a China fosse mais barata que o Canadá. Dessa forma, como os produtos são relacionados ao setor de plásticos (39), pode-se inferir que a China tem competitividade via preço em relação ao Canadá nesse setor. Além disso, percebe-se que o produto "Papel e artigos de papel" contribuiu para que a China fosse mais cara que o Canadá. Já o setor de ferro e aço (73) contribui predominantemente mais para que a China fosse mais barata que o Canadá.

No que diz respeito aos produtos tecnologicamente mais complexos, como os da tecnologia baseado em ciência, intensiva em escala e diferenciada, vale destacar a análise feita por Nonnenberg e Mesentier (2012) de que nenhum país seria tão competitivo quanto à China em produtos intensivos em conhecimento sem uma força de trabalho qualificada e uma indústria de transformação integrada e tecnologicamente avançada. Esses dois pilares da competitividade chinesa expostos pelo autor representam o esforço de análise do trabalho, principalmente, no sentido de constatar a maior complexidade da cadeia produtiva.

Vale ressaltar que esta primeira análise foi realizada de modo que não são os mesmos produtos para todos anos. Em outras palavras, dentro da mesma tecnologia, 
para 2013, existem produtos que já pertenciam à pauta desde 2001, porém também há produtos que saíram e outros que foram incorporados a pauta.

$\mathrm{Na}$ tentativa de acompanhar a evolução da mesma pauta de produtos foi construído outro indicador, no qual, além da interseção de produtos entre China e outro parceiro são os mesmos produtos para os anos de 2001 e 2013. Nesta análise, foram adotados os 1000 produtos da pauta de exportação da China e dos EUA. O intuito era agregar a maior quantidade de produtos possíveis, considerando a mudança na pauta de exportação chinesa, considerando a perda de produtos com o processo de compatibilização de pautas.

Em outras palavras, muitos produtos tiveram sua exportação reduzida e outros produtos foram inseridos, logo, torna-se mais difícil encontrar os mesmos produtos para anos tão distantes. Portanto, buscou-se aumentar o número de produtos na pauta ponderadora para que, ao calcular o indicador, houvesse o maior número de produtos possíveis dentro de um tipo de tecnologia. Na Tabela 2 observa-se o resultado encontrado.

Tabela 2: Evolução do diferencial de preços entre China, Alemanha, Canadá e México, segundo tecnologia, para os anos de 2001 e 2013 (para os mesmos produtos)

\begin{tabular}{llll}
\hline Tecnologia & País & 2001 & 2013 \\
\hline Diferenciado & México & $-53,30 \%$ & $-38,80 \%$ \\
Escala & Canadá & $1,10 \%$ & $-25,20 \%$ \\
Ciência & Alemanha & $-75,80 \%$ & $-75,80 \%$ \\
Rec. Nat & Canadá & $-48,10 \%$ & $-33,30 \%$ \\
Trabalho & México & $52 \%$ & $10,80 \%$ \\
\hline
\end{tabular}

Fonte: CEPII, 2013. Elaboração própria.

A primeira análise a ser feita é que se verificam diferentes movimentos em relação à trajetória de preços. Esperava-se que houvesse um movimento generalizado de aumento dos preços dos bens exportados chineses, por motivos diferentes, para cada tipo de tecnologia. Primeiro, haveria uma pressão para aumento de preços nos segmentos intensivos em trabalho, devido ao aumento salarial. Além disso, também haveria aumento dos preços dos bens intensivos em tecnologia, como ciência, escala e diferenciados, pois autores como Schott (2004), apontam que existe uma relação entre preço e intensidade de capital.

Schott (2004) utiliza dados em nível de produto das importações americanas, de 1972 a 1995. Ele encontrou três relações importantes: (i) uma relação de valor unitário maior das exportações para países de maior PIB per capita; (ii) os valores unitários estão correlacionados positivamente com a intensidade de capital utilizado em sua produção; (iii) países desenvolvidos apresentam um aumento do valor unitário ao longo do tempo. Porém, Schott (2004) encontrou que, embora os países exportassem o mesmo produto, este possuía preços diferentes. Ele afirma que essa diferença entre valores unitários estava associada ao que foi chamado de qualidade.

Nesse sentido, de analisar o preço estabelecendo uma relação de qualidade, Hiratuka e Cunha (2011) apresentam um estudo sobre a qualidade das exportações chinesas para o mundo. Salienta-se que houve um aumento da participação dos fluxos de baixa qualidade, em todos os tipos de tecnologia, com exceção nos fluxos mais intensivos em tecnologia ("fornecedores especializados" e "indústria intensiva em P\&D"), que apresentaram aumento de qualidade. Os autores trazem a ideia de Aiginger (2001) de qualidade, em que a mesma está ligada à dinâmica de concorrência dos 
mercados. Em outras palavras, a concorrência que se baseia na qualidade é mais acirrada e diferente da concorrência por preços.

A concorrência via qualidade se basearia no alcance de mercados que sejam mais inelásticos, ou seja, que apresentem menor sensibilidade de preços em sua demanda. Isso se dá por meio da inovação, diferenciação de produtos, marketing, dentre outros. Ou seja, a concorrência se dá pela busca da construção de ativos intangíveis capazes de se transformarem em ganhos de monopólios para esses produtores. Porém, para compreender o contexto de inovação chinês deve-se verificar a forma de difusão da inovação. Ao observar o funcionamento da inovação no contexto da empresa em rede, Sarti e Hiratuka (2010) verificam que a difusão da inovação não se dá de forma uniforme entre as empresas na cadeia global de valor.

As grandes empresas atuam como comandantes de uma grande cadeia de fornecedores dispersos ao redor do mundo. As empresas comandantes da cadeia detêm capacidades tecnológicas, principalmente ligadas à inovação, que as possibilitam se apropriem da maior parte do valor gerado. Os fornecedores dessas grandes empresas atuam em funções periféricas, com etapas padronizadas e definidas pelos comandantes da cadeia de valor. Por não dominarem os ativos intangíveis controlados pelas empresas líderes, os fornecedores se apropriam de menor parcela do valor criado.

Neste sentido, o processo de inovação é liderado por empresas que consigam coordenar as cadeias de valor, pois somente estas conseguem se apropriar da maior parte do valor gerado. Assim, as empresas que conseguem atuar mais fortemente em mercados caracterizados pela concorrência via inovação são justamente aquelas que conseguiram se inserir em elos mais nobres da cadeia produtiva global. Dessa forma, argumenta-se que embora a China tenha galgado avanços na fronteira tecnológica, para o segmento intensivos em escala, diferenciado e ciência, o país não foi capaz de se inserir em elos mais nobres da cadeia de produção de valor, mantendo-se em posições ainda periféricas.

Pode-se dizer que a produção de bens diferenciados se deu de forma mais madura, que possibilitou a inserção da China em elos mais nobres da cadeia produtiva. Como apontado por Pinto (2011), nestes segmentos, a China apresenta grandes corporações como Lenovo (computadores), a Huawei (equipamentos de telecomunicações), a Haier (eletrodomésticos e eletroeletrônicos). Isso ratifica a ideia de que a China foi capaz de construir dotações tecnológicas que lhe possibilitaram atuar, em alguma medida, como comandante da cadeia de valor e se apropriar de maior valor criado, neste segmento.

Também é importante destacar que os setores ligados à eletrônica receberam investimentos desde a abertura chinesa ao IDE. Isso se deu devido ao fato de a produção de eletrônicos ser mais facilmente modularizada, o que facilitou a dispersão da cadeia produtiva (ACIOLY, 2005). Logo, isso pode ter ajudado no amadurecimento da produção chinesa e consolidação de grandes grupos.

Faz-se uma ressalva com relação ao indicador desenvolvido à medida em que o mesmo não incorpora efeitos da inflação interna dos países analisados, que será objeto de esforços nos próximos estudos. Além disso, ressalta-se que foi realizada uma análise buscando identificar relações em relação ao movimento do câmbio dos países em análise para cada tecnologia e o movimento do indicador ao longo dos anos e percebeuse que as variações cambiais não auxiliavam na compreensão do movimento do indicador proposto. Com isso, a variável não foi considerada.

\section{Conclusão}


Percebe-se que a China conseguiu avançar em seu processo de catching up tecnológico, passando a ter tanto exportações quanto produções industriais mais intensivas em tecnologia. Até agora, a China conseguiu aliar vantagens competitivas em setores mais intensivos em mão de obra, quanto em setores mais intensivos em tecnologia.

Além disso, a China também demonstrou um forte crescimento de produtividade e também de aumento salarial. Não consenso, na literatura se o aumento salarial é superior ao aumento de produtividade, porém os dados indicam que os salários apresentaram aumentos superiores aos ganhos de produtividade.

Nesse sentido, a análise se preços buscou verificar o impacto das mudanças na estrutura produtiva, de produtividade e salários, e os impactos dos mesmos nos preços de bens industriais exportados ao mercado americano. Era esperado que houvesse um aumento de preços para a produção de bens diferenciado, baseados em ciência e escala. Porém, verificou-se movimentos distintos, com aumento dos preços para diferenciado e diminuição para baseados em ciência e escala. Portanto, ratifica-se a ideia de que a China tenha galgado importantes posições na cadeia de valor de diferenciado, mas não em escala e ciência.

Quanto aos dados sobre salários, esperava-se que houvesse uma pressão sobre os preços de bens finais, porém, verificou-se um processo de barateamento dos produtos intensivos em trabalho. Isso se dá pela própria dinâmica concorrencial nesses mercados que se dá, basicamente, via preço. Além disso, como apontado por Sarti e Hiratuka (2010) a China mostra uma capacidade dupla: não deixou de ter forte participação na produção de bens intensivos em trabalho, como vestuário e calçados, porém também conseguiu se inserir nos setores do novo paradigma tecnológico da época.

Dessa maneira, é possível dizer que se o processo de catching up tecnológico se aprofundar e a China conseguir desenvolver capacidades tecnológicas suficientes para comandar as cadeias globais de valor, então, talvez, seja o fim da China barata. Neste sentido, explicita-se que a maior parte da produção chinesa se deslocará para bens intensivos em tecnologia possivelmente em detrimento de bens intensivos em trabalho e/ou recursos naturais.

\section{Referências}

ACIOLY, L. China: uma inserção diferenciada. Rev. Economia política internacional: uma análise estratégica [S.1.], n. 7, out./dez. 2005. Disponível em: <http://goo.gl/j3zMdr>. Acesso em 15 set 2014.

AIGINGER, K. Measuring the intensity of quality competition in industries. WIFO. Quarterly. 2001. Disponível em: 〈http://goo.gl/B9KgJy>. Acesso em 21 nov 2015.

CEPII. Data (Trade Unit Value). Disponível em: $<$ http://goo.gl/IXK3Zf $>$. Acesso em 01 ago 2015.

CINTRA, M. A. M; PINTO, E.A. China em transformação: transição e estratégias de desenvolvimento. Texto para discussão n 006. IE/UFRJ. 2015. Disponível em: < http://goo.gl/m82hLx>. Acesso em 16 nov 2015.

COMTRADE. Trademap. Disponível em: 〈http:// goo.gl/3ZcI0J>. Acesso em: 04 abr 2015.

CUNHA, S. F.; XAVIER, C. L. Fluxos de investimento direto externo, competitividade e conteúdo tecnológico do comércio exterior da China no início do século XXI. Revista de Economia Política, vol. 30, no 3 (119), pp. 491-510, 2010.

DAVID, H; DORN, D; HANSON, H.G. China syndrome: local labour market effects of import competition in the United States. American Economic Review [S.1], v. 103, n. 6, p. 2121-2125. Oct/2013. 
GOUVEIA, E. M. Salários industriais, acumulação de capital e exportações na China. Dissertação de Mestrado apresentada ao Programa de Pós-Graduação em Economia Política Internacional, do Instituto de Economia/ Núcleo de Estudos Internacionais da Universidade Federal do Rio de Janeiro, 2012

HIRATUKA, C; CUNHA, S.F. Qualidade e diferenciação das exportações brasileiras e chinesas: evolução recente no mercado mundial e na aladi. IPEA. Brasília. Junho de 2011. Disponível em: 〈http://goo.gl/iqjvP7〉. Acesso em 16 dez 2015.

LARDY, N. China: The Great New Economic Challenge?. Institute for International Economics, Washington, DC, 2004.

LI, H. et al. The end of Cheap Chinese Labor. Journal of Economic Perspectives. n. 26, n. 4, p. 57-74. 2012. Disponível em: 〈http://goo.gl/2OHxvw〉. Acesso em $02 \mathrm{dez} 2014$.

MEDEIROS, C. A. Desenvolvimento Econômico e Ascensão Internacional. In: III Conferência Nacional de Política Externa e Política Internacional. Brasília: Fundação Alexandre Gusmão, 2008.

MEDEIROS, C.A. O ciclo recente de crescimento chinês e seus desafios. Observatório da economia global. Textos Avulsos, n. 3, junho/2010.

NONNEMBERG, M. J. B. Participação em cadeias globais de valor e desenvolvimento econômico. Boletim de Economia e Política Internacional. BEP.|n. 17 . 2014.

NONNENBERG, M.J.B; MESENTIER, A. Is China only assembling parts and components? The recent spurt in high tech industry. Rio de Janeiro. Rev. Econ. Contemp. v.16, n.2, 9. 287-315, mai-ago/2012. Disponível em: 〈http://goo.gl/4wyJZB〉. Acesso em 03 set 2014

PINTO, E.C. O eixo sino-americano e as transformações do sistema mundial: tensões e complementaridades comerciais, produtivas e financeiras. In: LEÃO, R.P.F; PINTO, E.C.; ACIOLY, L. (Org.). A China na nova configuração global: impactos políticos e econômicos. Brasília: IPEA, 2011. Capítulo 2. Disponível em: <http://goo.gl/mhRHB6>. Acesso em: 15 out. 2014.

RODRIK, D. What's so special about China's exports?. NBER, n. 1947. p. 1-27, 2006. Disponível: 〈http://goo.gl/MZic55>. Acesso em 15 nov 205.

SARTI, F.; HIRATUKA, C. Indústria mundial: mudanças e tendências recentes. Texto para discussão. IE/UNICAMP. n. 186, dez/2010.

SCHOTT, P. Across-product Versus Within-product Specialization in International Trade. The Quarterly Journal of Economics , [S.1.], v. 119, n. 2, p. 646-677, May 2004.

SCHOTT, P. Across-product Versus Within-product Specialization in International Trade. The Quarterly Journal of Economics. [S.1.], v. 119, n. 2, p. 646-677, May 2004.

The relative sophistication of Chinese exports. Yale School of Management. December 2008. Disponível em: 〈http://goo.gl/v1B2XI>. Acesso em 21 out 2015.

UNCTAD. Statistics. (UNCTADSTAT) Disponível em: <http://goo.gl/JFyA84>. Acesso em 17 jan. 2015.

Statistics. (UNCTADSTAT) Disponível em: <http://goo.gl/PHVp9H>. Acesso em 25 jan 2015

UNIDO. INDSTAT 2 2016, ISIC Revision 3. Disponível em: 〈http:// goo.gl/Wyg8as〉. Acesso em: 10 out 2015.

WORLD BANK. Data. Disponível em: <http://goo.gl/Q9OllO>. Acesso em 01 nov 2015 . 